\title{
Synthesis of Oxindoles, Spirooxindoles, and Isatins with Prominent Bioactive Probes: Review
}

\author{
Omprakash H Nautiyal* \\ Professor and Consulting scientist, India
}

Submission: February 10, 2018; Published: March 06, 2018

"Corresponding author: Omprakash H Nautiyal, Professor and Consulting scientist,Q/101, Manav Complex, Kalher, Bhiwandi, Thane 421302, India; Tel: 91-8733974519, Email: opnautiyalus@yahoo.com

\begin{abstract}
3-Hydroxy-2-oxindoles (Figure 1) are biologically useful active molecules, and efficient methods are needed for their synthesis under mild conditions. Wen-Ting Wei, have developed a base- and metal-free C $\left(\mathrm{sp}^{3}\right)$-H hydroxylation of 2-oxindoles. The reaction is promoted by TEMPO $(2,2,6,6$-tetramethylpiperidine $\mathrm{N}$-oxide) and synthesized under atmospheric air as a hydroxylation reagent in THF (tetrahydrofuran) at room temperature. Reaction mechanism proposed involves TEMPO reacting with the enol form of the 2-oxindole, followed by a reaction with $\mathrm{O}_{2}$ that generates a superoxide anion. This anion regenerates TEMPO and is converted to peroxide. Finally, the peroxide is cleaved to give the desired product. This concord provides a mild and simple strategy for the construction of C-O bonds from moderate to good yields. A wide range of substituted 2-oxindoles could be converted with a variety of functional groups.
\end{abstract}

Keywords: Hydroxylation; 2-0xindoles; Metal medited catalysis; Regio/stereoselctivity; Therapeutics

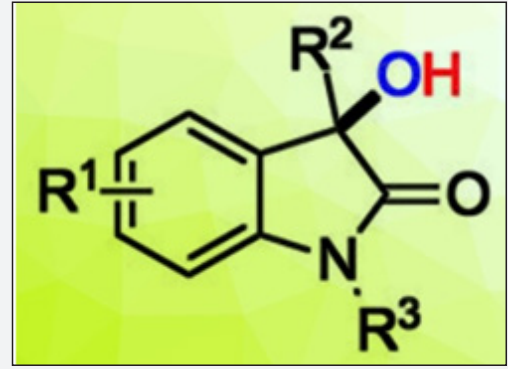

Figure 1: Hydroxy 2-Oxindole.

\section{Introduction}

Synthesis of 2-oxindoles presents a bewildering collection of diverse chemical functionality and properties [1]. Since they have co-emerged with their ostensive biological targets, natural products divide biological space with potency and fretful its function in a highly controlled manner (selectivity) $[2,3]$. Unsurprisingly natural products have abided as promising leads for drug discovery [4-7]. In context to their unprecedented structural diversity and biological activities oxindole natural products have continued to attract the interest of researchers and have been the interest of excellent reviews [8,9]. 3-substituted3-hydroxyoxindoles have remained less studied and obliviously impressive sub-class of oxindole natural products, which was not the subject of a review to date. The 3-substituted-3-hydroxy2-oxindole scaffold is being continuously discovered to be at the core of several natural products with a wide spectrum of biological activities. Unsurprisingly, the 3-substituted-3hydroxy-2-oxindole also found its interest as a target in drug discovery programs. Additionally being key intermediates towards complex natural product synthesis. The present review mentions the chemistry and biology of the 3-substituted-3hydroxyoxindole core in natural and synthetic compounds. 3-hydroxyoxindole core in the context of complex natural product structure with emphasis on sterically control and therefore covers the medicinal chemistry efforts in the use of the 3-hydroxyoxindole core as a privileged moiety in the search of potent therapeutic agents against cancer, HIV, growth disorders and other diseases. Finally the review concludes with an outlook towards the future areas of development in 3-hydroxyoxindole family of natural products and medicinal agents inspired by them. 
The compounds with complex functionalized are important molecules of interest for biological studies and as new molecules for pharmaceutical lead discovery. Oxindole and spirooxindole moieties have created considerable synthetic interest due to their presence in diverse natural products with notable biological activity. Recent discoveries of spiroindolone NITD609 have demonstrated nano molar activity being therapeutic agents that inhibits the blood stage of Plasmodium falciparum and has singledose efficacy in a rodent malaria model. Important biological activities have been demonstrated by various hydroxy-oxindoles scaffolds, such as Convolutamydine A, a natural product with potent activity against leukemia cells. Biological activities have also shown by substituted isatin (indole-2, 3-diones) scaffolds For example, isatin 1 is a potent inhibitor of SARS CoV 3C-like proteases. Efficient synthetic methods initially driven by the 1 , 2, 3-triazole 2 has now emerged as a heterocycle of biological interest in drug discovery and medicinal chemistry areas (Figure 2). For instance, triazole exhibits activity against tuberculosis strain H37RV. Oxindoles were observed with the significant biological activities and triazoles encourage the demand to develop efficient synthetic strategies to yield these scaffolds and increasing their structural diversity for drug discovery and medicinal chemistry proposes.

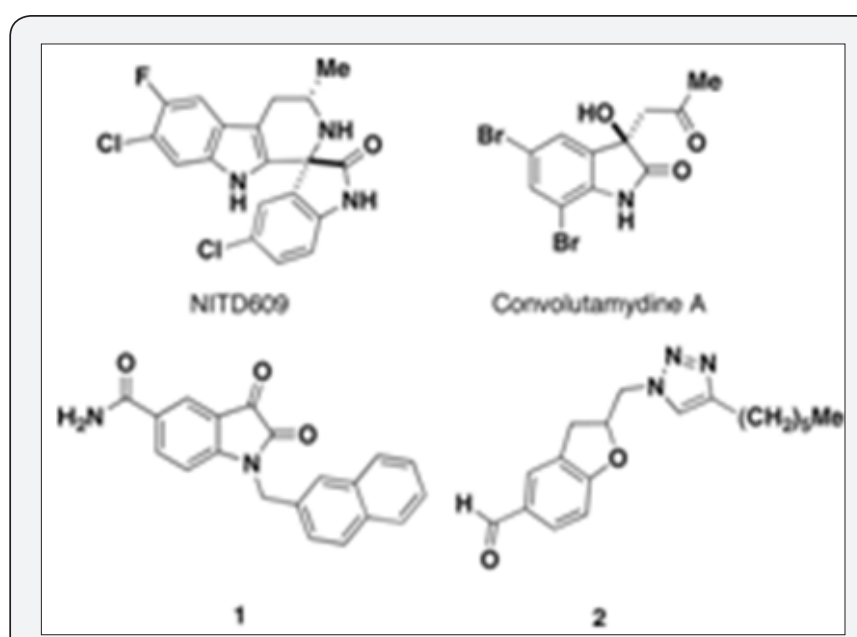

Figure 2 : Biologically active Oxindoles and Triazoles Jacob PM et al. [28]

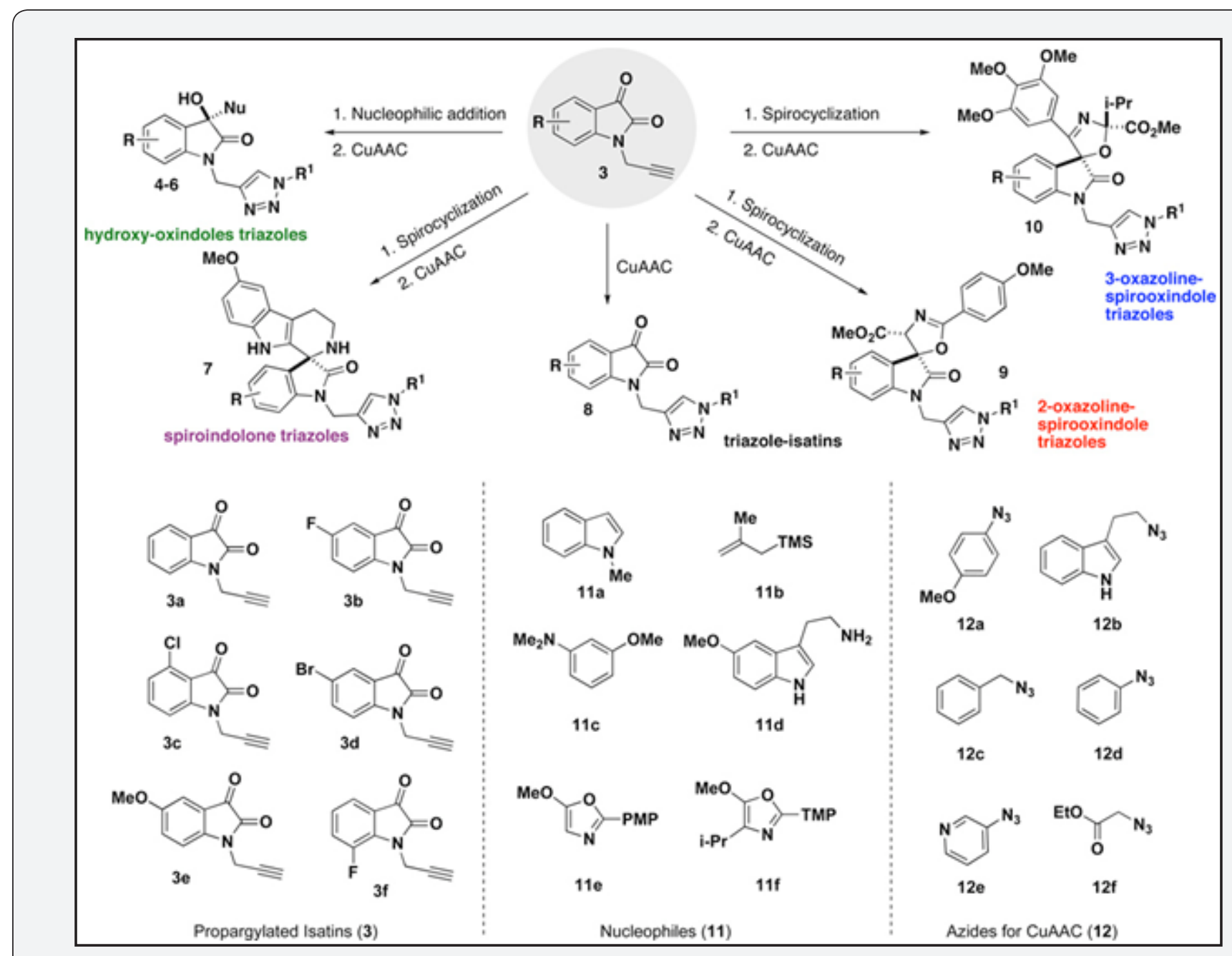

Figure 3 : Outline of synthetic strategy towards triazole-containing oxindoles (Jacob PM et al. 2012). 
Jacob PM et al. [10] has demonstrated several methods of catalytic activation of the isatin dicarbonyl for efficient and selective nucleophilic additions and spirocyclizations at the 3-position from their laboratory with previous work. Their strategy envisioned utilization of a common set of $\mathrm{N}$-propargylated isatins access diverse oxindole scaffolds through a series of nucleophiles with distinct mechanism in addition pathways. Each oxindole scaffold yielded contains an alkyne group with the provision of further opportunities for structural diversification with triazole heterocycles using the copper-catalyzed azide-alkyne cycloaddition (CuAAC) reaction. They envisioned that the $\mathrm{N}$-propargylated isatins would be directly utilized in the CuAAC reaction as a fifth scaffold because the reports and evaluation of biological activity unavailable with triazole-containing isatins. They have described their realization of the strategy for rapid access (two synthetic steps) to a pilotscale library of diverse triazole-containing hydroxy-oxindoles 4-6, spiroindolones 7, isatin-triazoles 8, and spirooxazolines 9-10 emanating from a common set of propargylated isatins 3. Overall their, our two-step strategy affords a library of 64 oxindole and spirooxindole compounds, including 15 core scaffolds and 49 triazole derivatives. (Figure 3) The efficient stereoselective syntheses of complex heterocycles combining both oxindole and triazole motifs have not been described previously. Based on the breadth of biological activity known for isatins, oxindoles and spirooxindoles, these densely functionalized heterocycles should serve as important biological probes for chemical biology.

Several methods of catalytic activation of the isatin dicarbonyl has been demonstrated in their laboratory for efficient and selective additions of nucleophiles and spirocyclizations at the 3-position. Their envisioned strategy employs a common set of N-propargylated isatins to yield diverse oxindoles through a series of nucleophiles with distinct mechanism with addition pathways. Oxindoles yielded found to contain an alkyne group providing further opportunities with diversifying structures with triazoles heterocycles employing the copper catalyzed azide aklyne cycloaddition reaction. They further envisioned that N-ppropargylated isatins would be directly employed in the CuAAC reaction as a fifth scaffold. Because isatins bearing triazole were not in the past reported and/or evaluated for their biological activity. So they described their strategy with their realization for rapid access (bisteps) to pilot scale record of diverse triazole containing hydroxyl oxindoles, spiroindolones, isatin triazoles and spirooxazolines yielded from a same set of propargylated isatins. Their two step strategy overall afforded a library of 64 oxindoles and spirooxindoles compound with inclusion of 15 care scaffolds and 49 triazoles derivative. Previous description mention not the efficient stereoselctive syntheses of complex heterocycles containing both oxindole and triazole moieties as investigated by them. Isatins, oxindoles and spirooxindoles known for their breadth biological activity with densely functionalized heterocycles shall serve as vital biological probes for chemical biology.

\section{Results and Discussion}

\section{Synthesis}

Addition of Carbon Nucleophiles to Oxindoles: Organic synthesis and the formation of new carbon-carbon bondformination reactions are of great interest in organic synthesis. Nucleophilic addition to isatins via aldol condensation and/or metal catalyzed is the most direct approach to 3-substituted3-hydroxyoxindoles. Addition of carbon nucleophiles to ketone forming quaternary carbon centers is a major challenge and has stimulated many organic chemists. With the purview of literatures it is encouraging that the challenging absolute control of the quaternary center in case of 3-substituted-3hydroxyoxindoles has been successful.

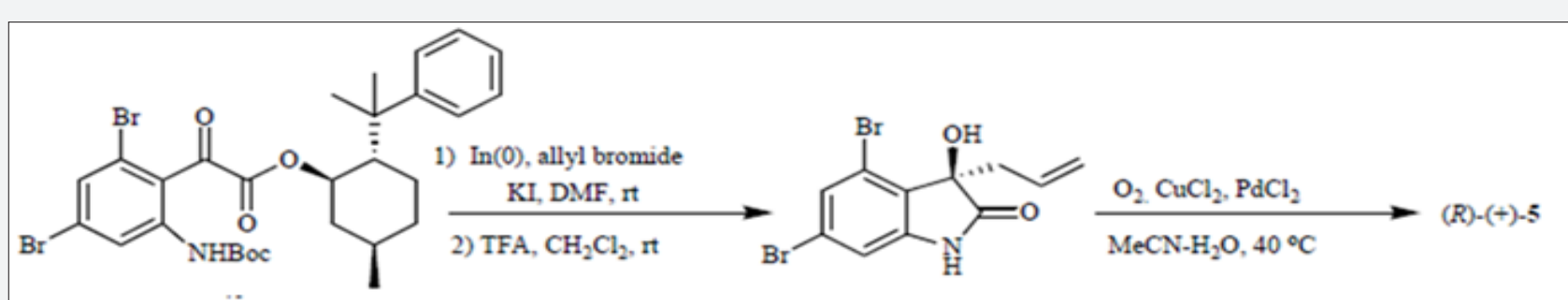

\section{$(1 \mathrm{R}, 2 \mathrm{~S}, 5 \mathrm{R})-8$-phenylmenthyl ester 1}

Figure 4 : Enatioselective synthesis of (+)-convolutamydine A (5) via In-mediated allylation.

Metal Mediated Catalysis: In parallel to the nucleophilic addition to the 3-carbonyl of isatins as a blue print for the synthesis of 3-alkyl/3-aryl-3-hydroxyoxindoles and/or metalmediated addition of carbon nucleophiles/equivalents has been attained. (Figure 4) Allylation and propargylation/allenylation of carbonyls with organometallic reagents such as the Sakurai-, Grignard-, and Barbier-type reactions are among the most basic and established reactions for constructing carbon-carbon bonds $[10,11]$. The chemo- and regioselectivitiy of the targeted alcohols in such reactions are controlled by the nature of the 
metals employed. However, researches on the extension of these methods to isatins, is very scarce due to discouraged synthetic interest owing to the low regioselectivity of the propargylic/allenic reaction site [12]. The convincing properties of organometallic reactions in aqueous phase including unique reactivity and selectivity, independence from protectiondeprotection strategy and environmentally benign chemical process led Alcaide and co-workers to investigate reactions of isatins with stabilized organometallic reagents in aqueous media $[13,14]$. Isatins and a variety of stabilized organic halides were found to undergo coupling under Barbier-type conditions in the presence of different metals (indium, tin, zinc) and additives (ammonium chloride, hydrobromic acid, bismuth (III) chloride, hafnium (IV) chloride).

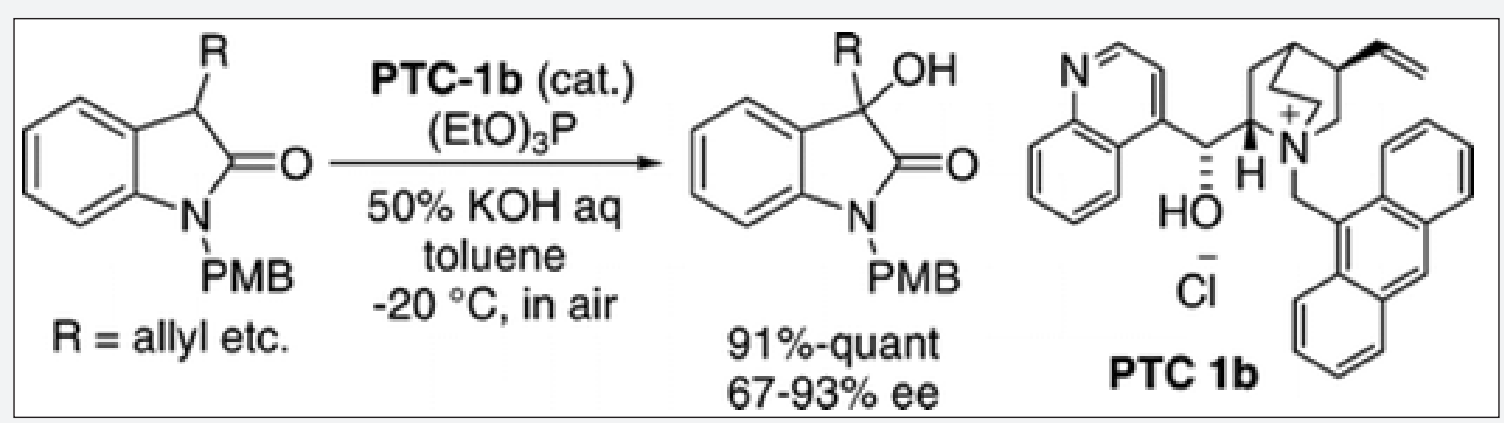

Figure 5 : enantio selective catalytic hydroxylation of 3-substituted oxindoles

The regiochemistry of the processes (carbonylallylation, bromoallylation, 1, 3-butadien-2-ylation, propargylation, or allenylation reactions) were generally excellent making these processes very appealing to be applied in synthesis of natural products. In fact, recently established the absolute configuration of (+)-convolutamydine A as (R) by enantioselective synthesis using allyl indane addition to (1R, 2S, 5R)-8-phenylmenthyl ester 1 based on a chiral auxiliary-directed-face discrimination
[15-17]. Out of the several methods currently available to obtain homoallylic alcohols the authors opted for indium-mediated allylation because of a simple and mild procedure, high yields and nontoxic nature of the indium metal. Finally, Wacker oxidation of 2 was carried out to afford enantiopure (R)-(+)convolutamydine A. For an independent and unequivocal proof, the absolute stereochemistry of synthetic precursor 1 en route to product was determined by X-ray crystallography.

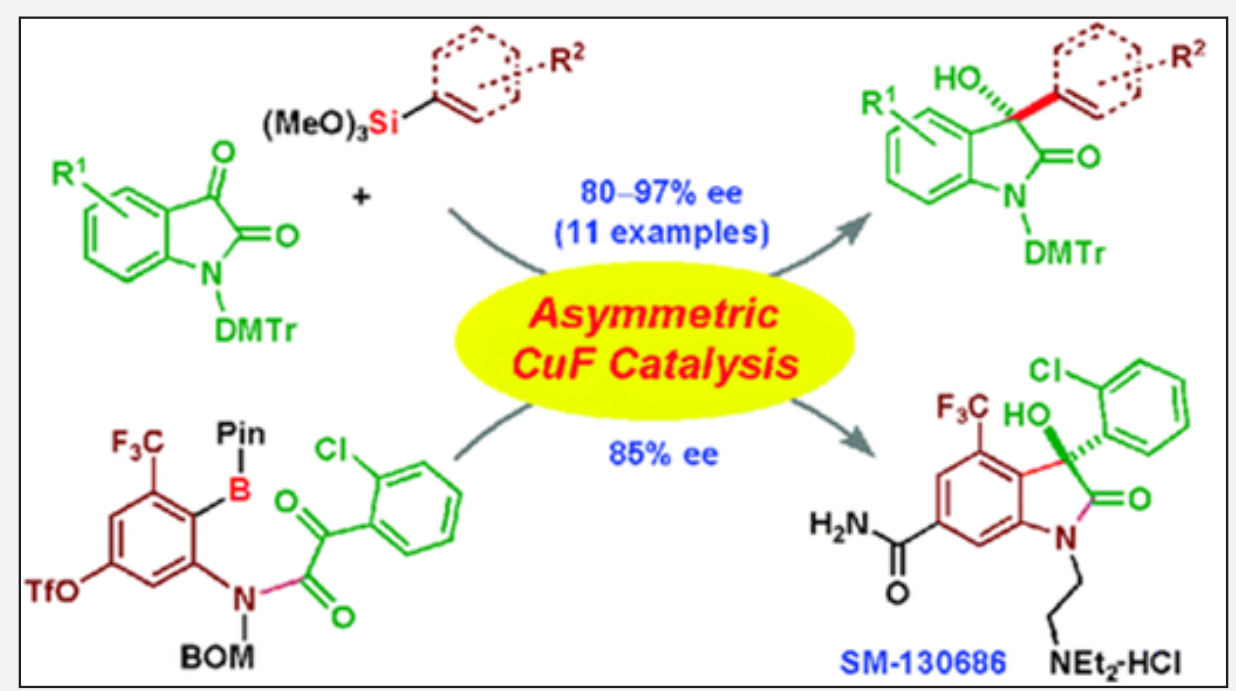

Figure 6 : enantioselective arylation and alkenylation using aryltrimethoxysilanes and alkenyltrimethoxysilanes as nucleophiles with catalysis by a complex of CuF with Taniaphos.

Diasuke Setal. [18] in 2008studied the highly enantio selective catalytic hydroxylation of 3-substituted oxindoles (Figure 5) was obtained employing a phase-transfer catalyst with molecular oxygen as an oxidant. The product on conversion yielded an optically active compound, which was a synthetic precursor of alkaloid CPC-1.3-aryl-and 3-alkenyl-3-hydroxy-2-oxindoles were developed (Figure 6) by two different catalytic enantioselective approaches by Daisuke Tomita et al. [19]. Reaction of isatins conducted with enantioselective arylation and alkenylation using aryltrimethoxysilanes and alkenyltrimethoxysilanes as nucleophiles with catalysis by a complex of CuF with Taniaphos, structurally tuned in the presence of $\mathrm{ZnF}_{2}$ as catalytic amount. 
In defiance the wide substrate scope, they found intermolecular reaction was not applicable to a catalytic enantioselective synthesis of SM-130686(1). They found that highly potent, orally active growth hormone secretagogue with sterically congested chiral tetrasubstituted carbon. Therefore, they developed an intramolecular catalytic enantioselective arylation of $\alpha$-keto amides, with advantage of the robustness of arylboronate reagents under multiple synthetic conversions and silica gel column chromatography purification. Enantioselective arylation of $\alpha$-keto amide catalyzed with a complex of CuF with Ph-BPE that yielded product in $85 \%$ ee. $\mathrm{ZnF}_{2}$ addition as catalyst to this intramolecular reaction was not necessary. SM-130686 the first enantioselective synthesis was achieved using this catalytic methodology. Since 2-oxyindoles are a versatile theme for biologically active compounds, the two types of $\mathrm{Cu}$-catalyzed asymmetric reactions developed will be useful for the synthesis of other natural products and pharmaceutical leads.

Peddibhotla S [19] in his review has mentioned that natural products and small molecules inspired by them are enjoying a resurrection of interest because they criss crossing biological space effectively and selectively. On account of their unrivalled structural diversity and biological activities oxindole natural products continue to attract the interest of chemists and biologists alike. Quarternary or spirocyclic 3-alkyl (aryl)-3-hydroxy-2oxindole scaffold is at the core of several natural products with a wide spectrum of biological activities. Concurrently the extraordinary progress in the development of selective synthetic methods, a number of drug discovery programs have recently begun to recognize the importance of this 'dispensation' scaffold, due to their potent anti-oxidant, anti-cancer, anti-HIV, neuroprotective and other biological properties and manifold modes of action of such class of natural products and analogs of theirs. There is strong incitement for the continued synthesis of novel diversity literatures based on the 3- substituted-3-hydroxy2-oxindole core for the prospective treatment of proliferative and other diseases with clear understanding of underlying cellular pathways involved. Factually, this process is underway as epitomized by the recent synthesis of novel spirocyclic tetrahydrofuran- and isoxazolidine-2-oxindole libraries capable of attaining growth inhibition of lung adenocarcinoma (A549) cells, hepatocellular carcinoma (HepG2) cells and human breast cancer cell line, MCF-7. This review covers the isolation, diverse structure, activity, synthesis, and known medicinal chemistry of 3- substituted-3-hydroxy-2-oxindoles [19,20].
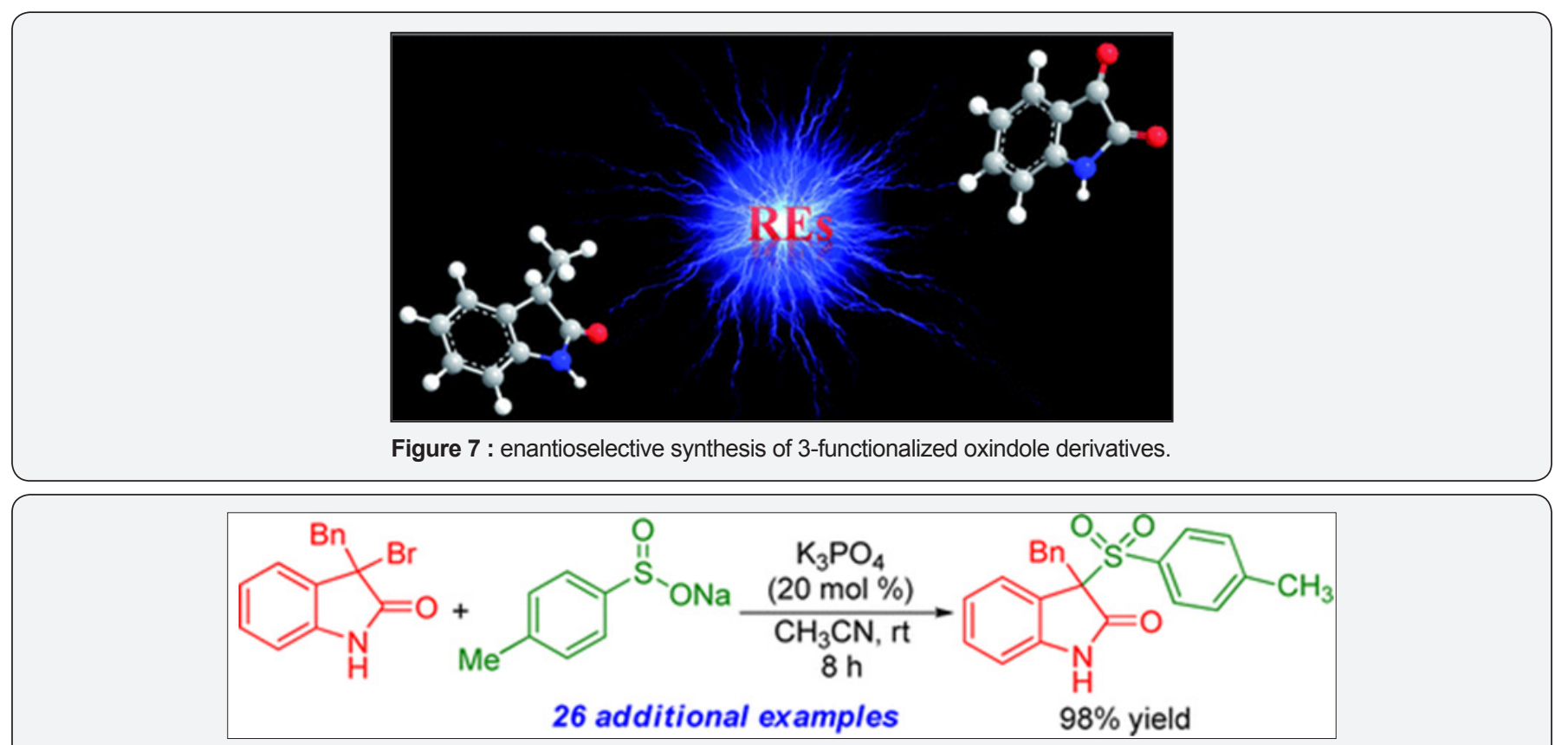

Figure 8 : the preparation of 3-sulfonylated 3, 3-disubstituted oxindole derivatives.

Ke Shen et al. [21] studied the enantioselective synthesis of 3-functionalized oxindole (Figure 7) derivatives with an experience of an explosive development. Their mini review introduces the recent application of rare earth (RE) metal complex catalysts in the synthesis of targeted frameworks. The direct addition reactions of 3-substituted oxindoles or isatins are described, together with a discussion of the catalytic mechanism and related transformations to pharmaceuticals. Jian Zuo et al. [22] (Figure 8) demonstrated an efficient method for the preparation of 3-sulfonylated 3, 3-disubstituted oxindole derivatives has been developed. The protocol involves a basecatalyzed addition of sulfinate salts to 3 -halooxindoles, affording a wide range of 3-sulfonylated 3, 3-disubstituted oxindoles in good to excellent yields under mild conditions. A preliminary trial of asymmetric catalytic version was conducted and gave promising enantioselectivity. The mechanism for the reaction was tentatively explored with the help of mass spectrometric analysis. Takashi Ooi et al. [23] studied the Conversion of hydrogen peroxide into an electrophilic hydroxylating agent by activation with an electrophile can be an indigenous pattern 
to achieve hydroxylation of nucleophilic reagents, such as enolates, (Figure 9) specifically if the transformation can be performed in a stereo controlled manner. Recently, they have reported the successful enantioselective conversion of oxindoles into $\alpha$-hydroxy-oxindoles using $\mathrm{H}_{2} \mathrm{O}_{2}$ as the oxidant. The in situ activation of aqueous hydrogen peroxide with trichloroacetonitrile enables direct enantioselective transfer of the hydroxyl group to the $\alpha$-position of oxindoles under catalysis with chiral 1,2,3-triazolium salts. Systematic structural variation (Figure 10) with vast variety of aryl groups was disallowed for the preparation of 3-alkenyl or 3-aryl-3-3-hydroxyoxindoles as approached in the literature to study the biological effects of these hydroxyoxindoles. Rhodium catalyzed additions of sp2-hybridized carbon nucleophiles inspired by this progress to a variety of electrophiles and studied by de Vries and co authors investigated 1, 2-addition of arylboronic acids to isatin substrates on the basis of combination of rhodium (I) precursor and 2 equiv of triphenylphosphite. Hillgren, et al. [25] studied the Conversion of hydrogen peroxide into an electrophilic hydroxylating agent by activation with an electrophile can be an indigenous pattern to achieve hydroxylation of nucleophilic reagents, such as enolates, specifically if the transformation can be performed in a stereo controlled manner have reported their study on a convergent synthesis of 3-alkoxy-3-aryloxindoles from readily available 2-bromoanilines and mandelic acid derivatives employing Pd-catalyzed intramolecular arylation of the alkoxy enolate of the resulting o-haloanilide. The results of screening and optimization of best conditions are shown in Figure 9. The reaction was found to be tolerant to substitution on both of the aryl rings, mandelate and aniline. In fact N-benzyl substituent on the aniline was found to be suited for the reaction. The electron withdrawing $\mathrm{N}$-sulfonyl and $\mathrm{Cbz}$ groups were not. Free $\alpha$-hydroxy groups are not tolerated was another limitation of the reaction. The use of simple was starting materials however with convergent nature and potential for asymmetric synthesis, being considered this an attractive approach to be pursued further. Nucleophilic addition to isatins is an alternative electrophilic oxidation of 3-alkyl or 3-aryl-2-oxindoles.

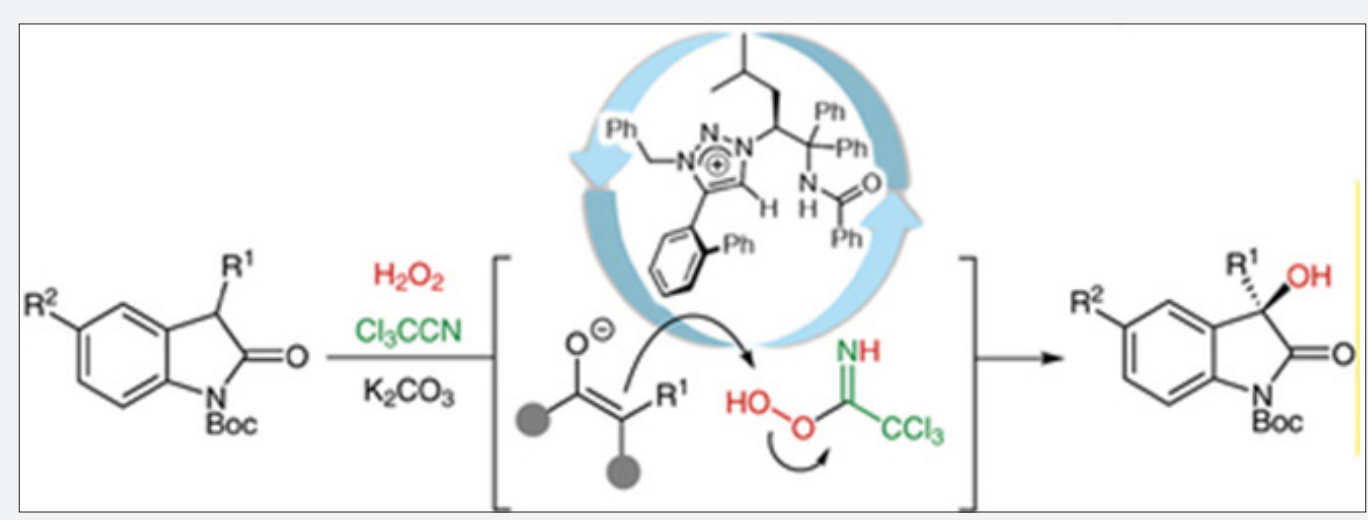

Figure 9 : enantioselective conversion of oxindoles into $\alpha$-hydroxy-oxindoles using $\mathrm{H}_{2} \mathrm{O}_{2}$ as the oxidant.

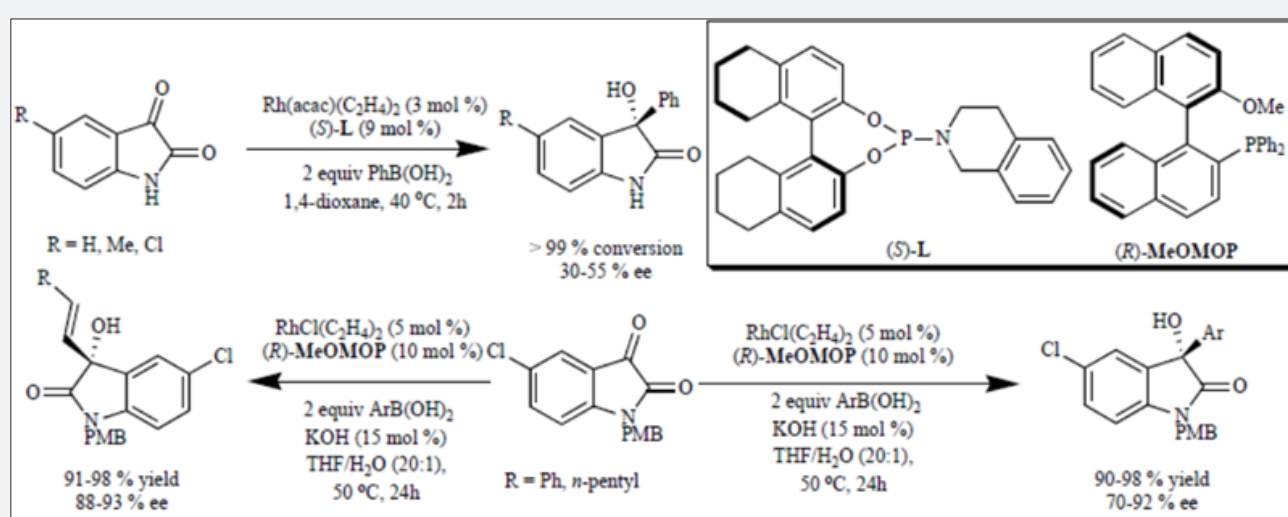

Figure 10 : Enantioselective addition of aryl/alkenyl boronic acids to isatins; a) top panel: de Vries' method, b) bottom panel: Hayashi's method.

In the past there are reports of an asymmetric hydroxylation of 3-substituted-2-oxindoles using in stoichiometric amount of a chiral oxaziridine (Davis reagent) [24]. There have been recent reports from researchers of Shibata and Toru groups of the method for the catalytic enantioselective hydroxylation of 2-oxindoles to make use of the DBFOX-Zn(II) catalyst with oxaziridine as a stoichiometric oxidant [25]. Optimized conditions were led by screening of Lewis acids, solvents and different oxaziridines as shown in (Figure 11) that gave excellent yield and high enatioselectivities for a wide range of 3-alkyl and 3-aryl-3-hydroxy-2-oxindoles. On the other hand employing organocatalytic oxidants requires separation of byproduct from the product, molecular oxygen being inexpensive stands a clean oxidant, without any byproducts and is environmentally 
safer. Already investigated base-mediated hydroxylation of 3-substituted oxindoles with molecular oxygen, Itoh and coworkers attempted to develop an asymmetric version employing chiral ammonium salts (phase-transfer catalyst). The authors on screening for best conditions revealed them that cinchonidine derived phase-transfer catalyst, toluene as biphasic solvent and 4 equivalents of triethyl phosphite gave the highest yields. Under those conditions hydroxylation of N-PMB protected 3-allyl-2- oxindole yielded the 3-hydroxy product in 98\% yield and $85 \%$ (Figure 11). This product was then elaborated to the synthesis of alkaloid CPC-1 to previously reported intermediate. Gave one of the earliest contributions towards air oxidation as a strategy who were the first to report the total synthesis of a member of the convolutamydine family of natural products. Their synthesis is the only known synthesis of convolutamydine C [26].

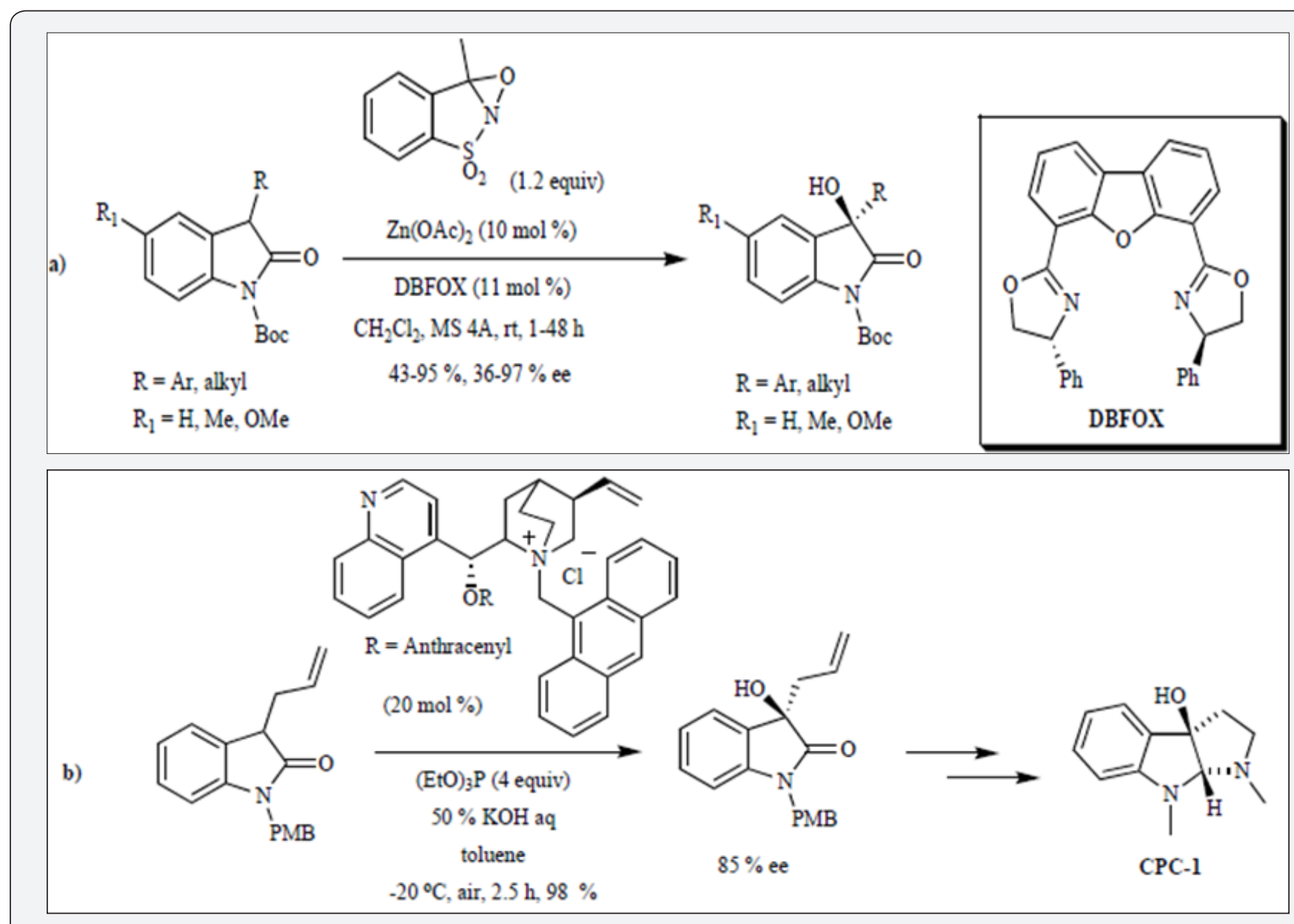

Figure 11 : Oxidative synthesis of 3-substituted-3-hydroxyoxindoles.

Jacob PM [27] strategies were of the key feature that has regio-, diastereo- and enantioselective synthesis of the oxindole and spirooxindole scaffolds (Figure 12). On the basis of the nucleophilic component (1) they have utilized, four oxindole scaffolds selected for this work: hydroxy-oxindoles 3-5 are prepared with chiral Lewis acid catalyst with enantioselectivity (9); spiroindolones 6 are prepared with chiral Bronsted acid catalyst with enantioselectivity (10); and the 2-oxazoline and 3-oxazoline spirocycles 7 and 8 are each prepared with titanium (IV) Lewis acid catalyst diastereo- and regioselectivity. For ensuring high selectivity some scaffolds, isatins (3) are selected based on substitution patterns.

Firstly they have investigated a series of 3-substituted-3hydroxy-oxindole scaffolds 3-5 using scandium (III)-catalyzed enantioselective additions with representative $\pi$-nucleophiles: $\mathrm{N}$-methylindole (1a), 2-methallylsilane (1b), and $\mathrm{N}, \mathrm{N}$-dimethyl$m$-anisidine (1c). Scandium(III) complexes were prepared with the 2,6-bis[(3aS,8aR)-3a,8a-dihydro-8H-indeno[1,2-d] oxazolin2yl]pyridine ligand (e.g. 9) are established to be effective chiral Lewis acid catalysts with appreciable chelating potential. Isatins were utilized to afford hydroxy oxindoles with high yields (78$97 \%$ ) and enantioselectivity (85-99\%). They performed all reactions at room temperature, with the exception of entries 1 and 4 , which were performed at $-20^{\circ} \mathrm{C}$ as of their high reactivity of the nucleophile. In the case of the methallylsilanethe reaction is carried out in acetonitrile with $\mathrm{TMSCl}$ and $\mathrm{NaSbF}_{6}$ as to enhance the efficiency of the reaction and facilitates in situ deprotection of any resulting OTMS product so as to obtain that the hydroxyoxindole products exclusively [28,29]. 


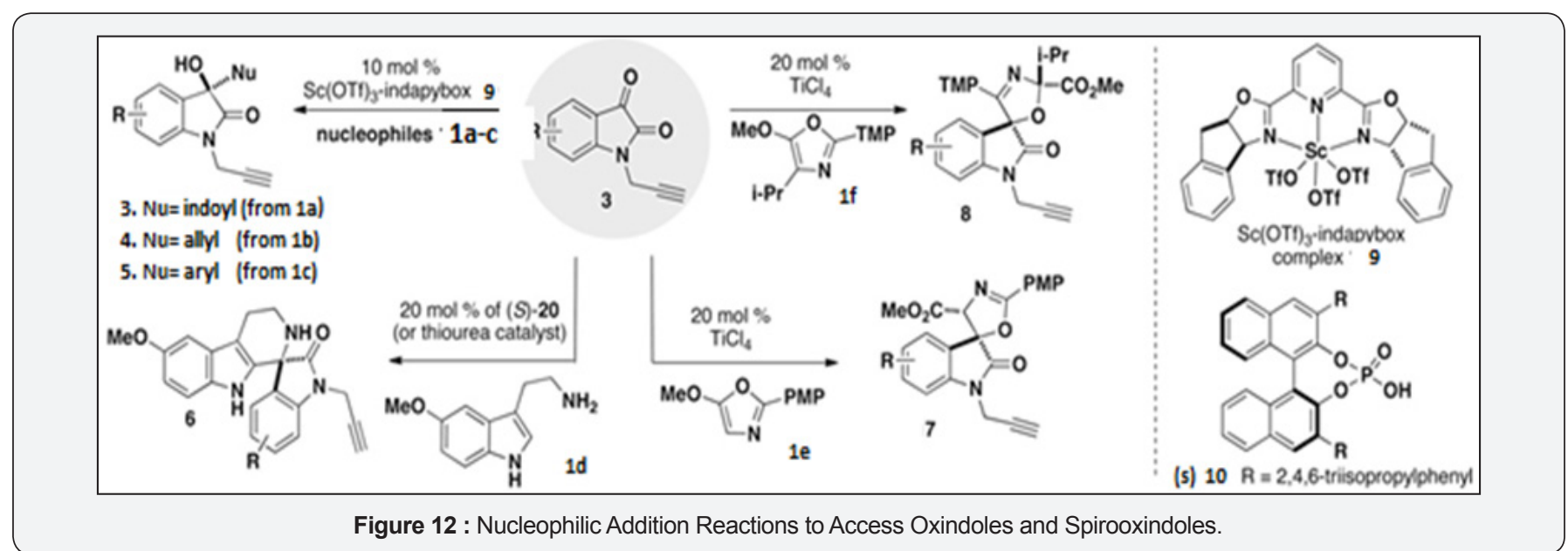

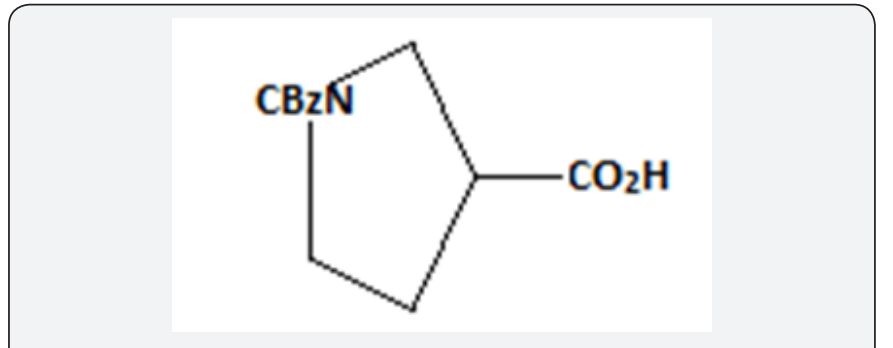

Figure 13: Amino acid employed.

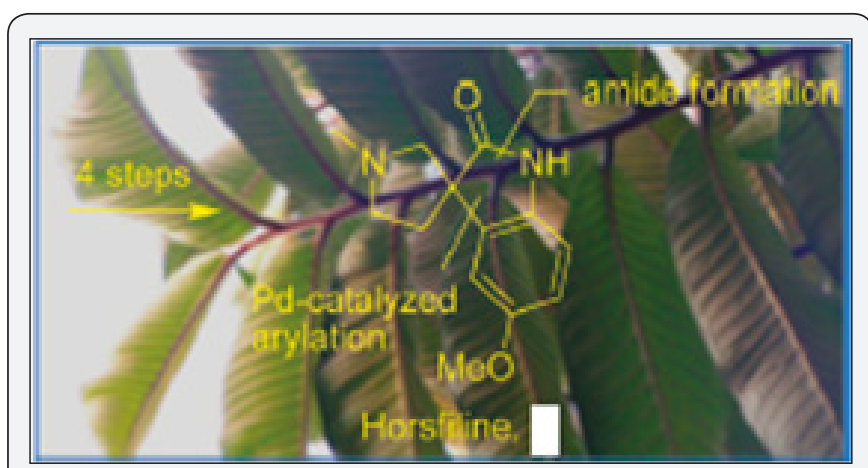

Figure 14 : Horsfiline (spirooxindoles).

Short synthesis of Horsfiline (Spirooxindoles): Deppermann et al. [31] synthesized the functionlized spirooxindoles by the Pd-catalyzed intramolecular $\alpha$-arylation of amides. On evaluating the substrate scope the reaction was demonstrated to be useful for the assembly of spirooxindole natural products and derivatives thereof. Their application presented a new synthesis in only 4 steps from commercially available amino acid (Figure 13) of horsfiline, (Figures 14-16) the natural product. The key step of their concept was the Pd-catalyzed $\alpha$-arylation of an appropriate amide precursor 3 . Hartwig has reported this reaction has first for inter- and intramolecular variants. 11 the method however has rarely been used for the synthesis of spiro compounds, nor has it been employed to the synthesis of densely functionalized natural products. The authors in consequence firstly focused on few model reactions for evaluating the substrate scope and optimal conditions for the attempted $\alpha$-arylation. They have shown two examples 9a and $9 \mathrm{~b}$ for synthesizing the required cyclization precursors and rest of the anilides 9c-9f were synthesized in one or two steps. They have carried the cyclization of anilides 9a, 9c, 9d using the Lee and Hartwig [30] conditions $\left(\mathrm{Pd}(\mathrm{PCy} 3)_{2}\right.$ in dioxane $55^{\circ} \mathrm{C}$. They observed the smooth functioning of the reaction and have yielded the desired spirooxindoles 10a, 10b, 10c in good yields. The detectable byproducts were dehalogenated anilides methyl in $(9 c, 9 d$, and 9f) here.

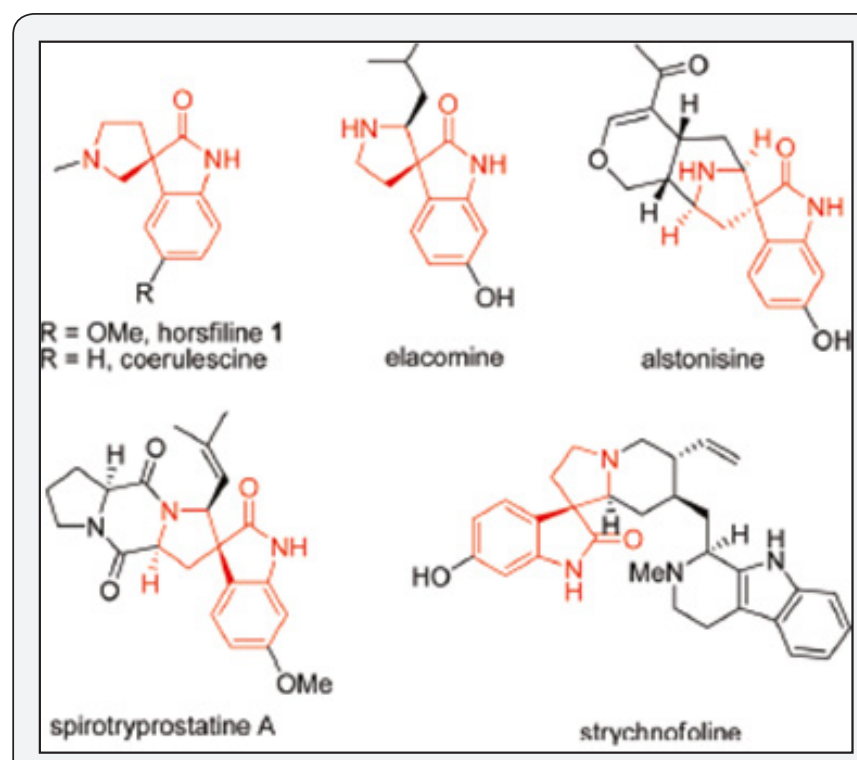

Figure 15 : Few examples of bioactive natural products containing 3, 3'-pyrrolidinyl-spirooxindoles (marked in red).

Generally N-Alkyl and N-benzyl groups are well tolerated, but the SEM protected anilide 9a conversion the using the above-mentioned conditions $\left(\mathrm{Pd}(\mathrm{PCy} 3)_{2}\right.$ in dioxane, $\left.55^{\circ} \mathrm{C}\right)$ did not give the desired spirooxindole $10 \mathrm{a} .12$ Their findings were the same for the conversions of nipecotic acid derivatives like 9e or cyclohexyl carboxamides like 9 f under the ditto conditions. However, their switching the solvent to toluene and increasing the temperature improves the condition, and a good yield of spirooxindole 10a was obtained upon conversion of anilide 9a with $\mathrm{Pd}(\mathrm{PCy} 3)_{2}$. They obtained the best results with the $[\mathrm{Pd}]-$ 
PEPPSI catalyst 13 in toluene at $110^{\circ} \mathrm{C}$. There are previous reports on this catalytic system to give excellent results for the $\alpha$-arylation of sterically hindered substrates by Hartwig [33] 11a Even SEM-protected anilides, using these improved conditions, like 9a, sterically hindered and functionalized derivatives of cyclohexane carboxamides like 9f, or heterocycles like 9e gave the corresponding spirooxindoles 10 in good yield.

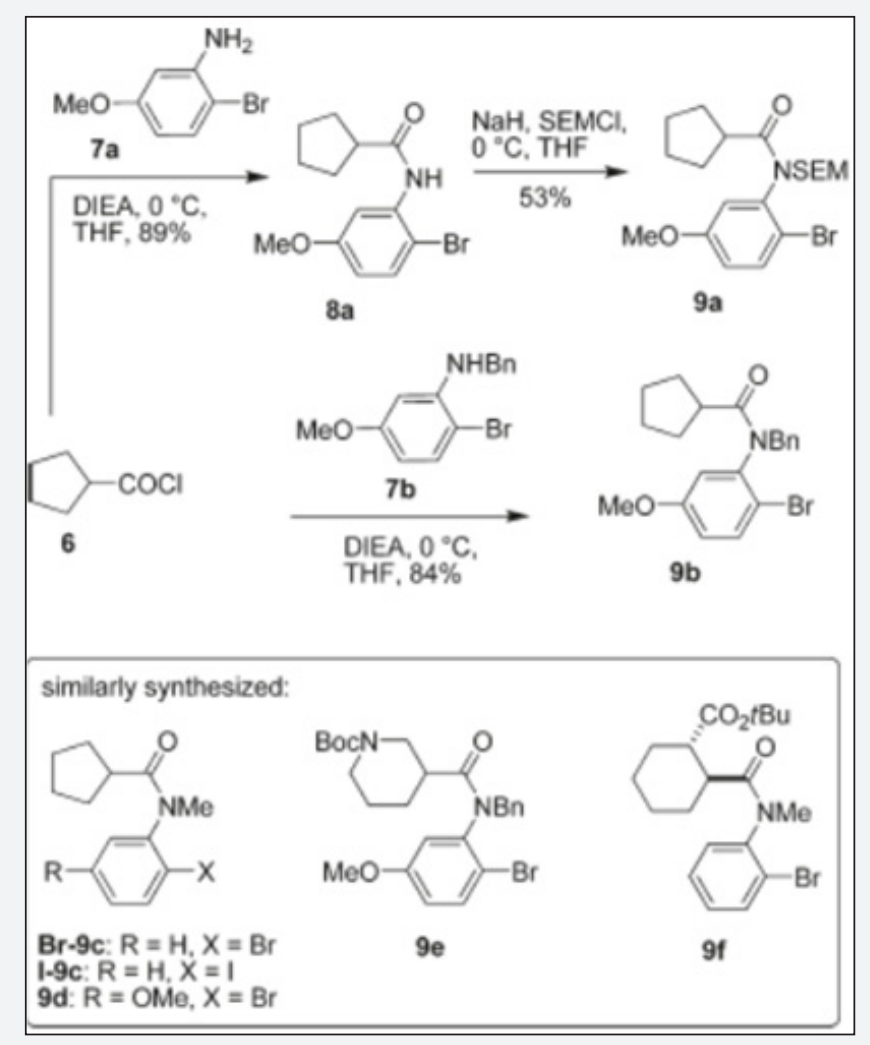

Figure 16 : Synthesis of cyclization precursors.

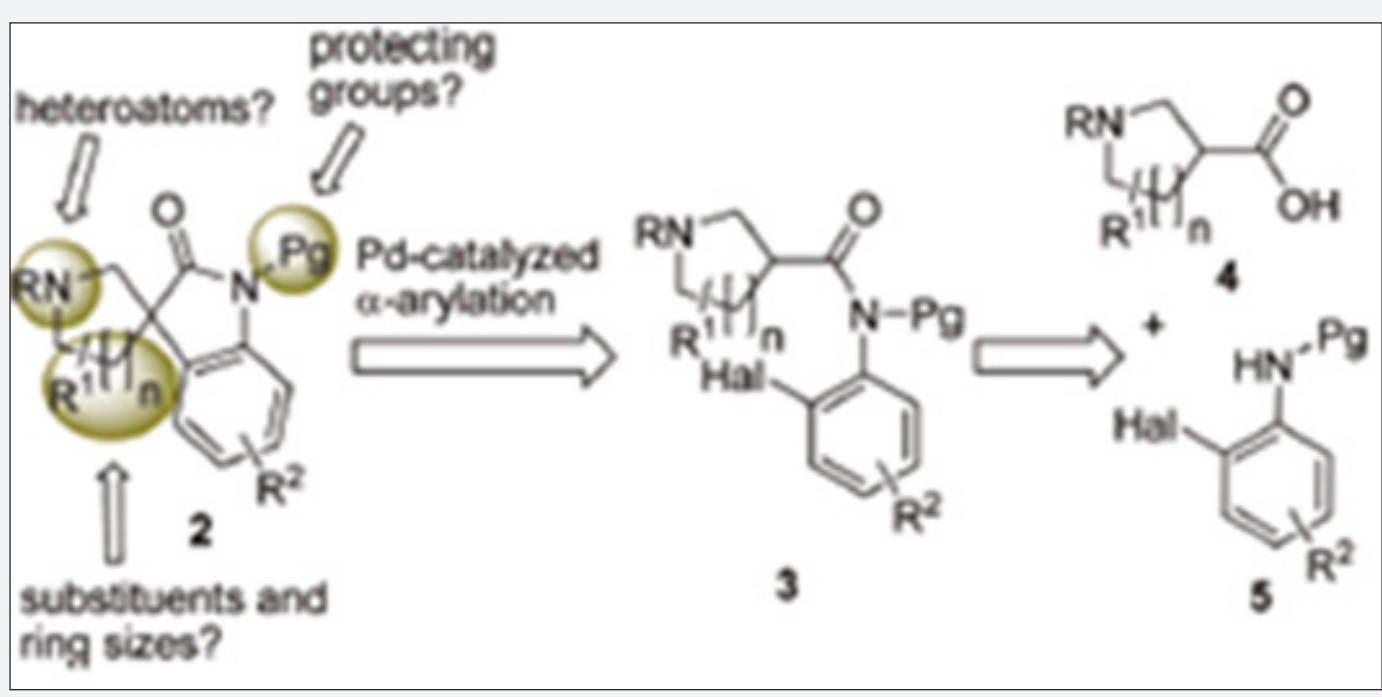

Figure 17 : Retrosynthesis of spirooxindoles scaffolds 2.

Their approach is presented in (Figure 17). Their plan was to construct the spirooxindole 2 by an intramolecular $\alpha$-arylation of the intermediate o-haloanilide 3. Preparing this intermediate would be by reacting carboxylic acids 4 and anilines 5 by amide formation. This method is being attractive in particularly, because many derivatives of both adducts (anilines 5 and carboxylic acids 4) are commercially available or can be synthesized with limited efforts for more complex derivatives. The authors have presented their reaction evaluation and conditions for synthesizing Horsfiline in Table 1. 
Table 1: Evaluation of reaction scope and conditions.

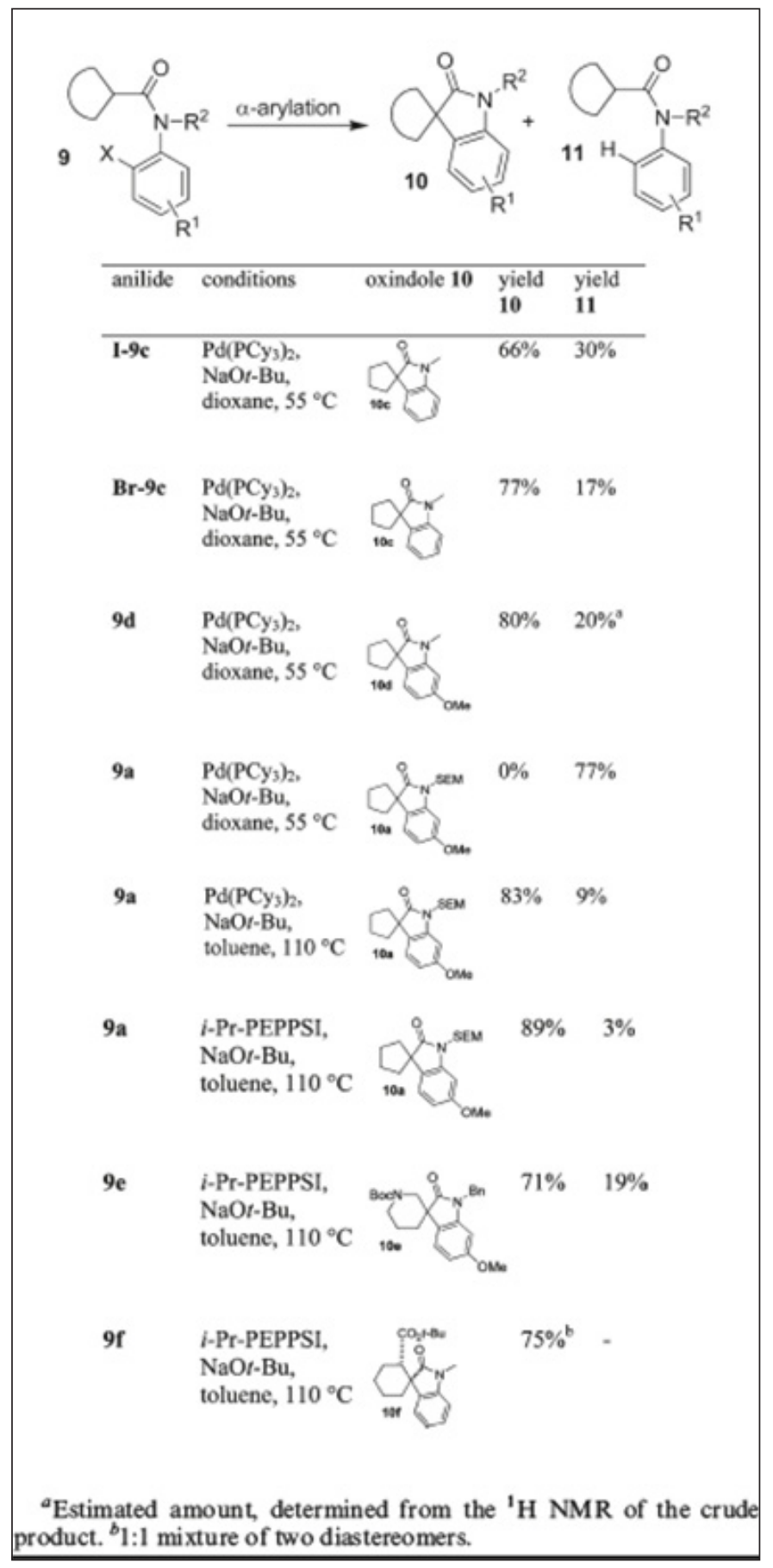

The retrosynthesis as shown in Figure 17, the $\alpha$-arylation of anilides was applied to a short total synthesis of $( \pm)$-horsfiline 1 . The isolation of this spirooxindole was carried and obtained first isolated from the Malaysian tree Horsfieldia superba in 1991 by Bodo [34]. It has been used frequently to demonstrate the power of novel methodology in natural product synthesis and as a model compound. There are reports of number of syntheses in the literature. Authors begun with the commercially available Cbzprotected pyrollidine-2-carboxylic acid 12, which on coupling to the anilide $7 \mathrm{c}$ with $\mathrm{PCl} 5$ gave 13 in good yield (Figure 18). 16 The $\alpha$-arylation of 13 with the [Pd]-PEPPSI-catalyst system at $110^{\circ} \mathrm{C}$ gave spirooxindole 14 in excellent yield. Conversion of the starting material was complete, and no dehalogenation was observed. Spirooxindole 14 is a known precursor for horsfiline. With a slight modification of a known procedure to 11 . The reaction works for aryliodides like I-9c and arylbromides like Br$9 \mathrm{c}$ or $9 \mathrm{~d}$, the latter giving less debromination as a side reaction. In consequence, Deppermann et al. have used arylbromides for following conversions $15 \mathrm{e}$ we have been able to convert Cbzprotected 14 to N-Bn-horsfiline 15 by Cbz-deprotection and reductive amination with paraformaldehyde in one step. They were not able to deprotect $\mathrm{Cbz}$ and $\mathrm{Bn}$ in 14 simultaneously as suggested by Cheng et al. [31], Kung. 15l Even with increase in the hydrogen pressure up to 20 bars did not cleaved of the N-benzyl amide. But, unwanted side reactions such as ring opening of the spirocycle 14 were observed instead by them [33-36].

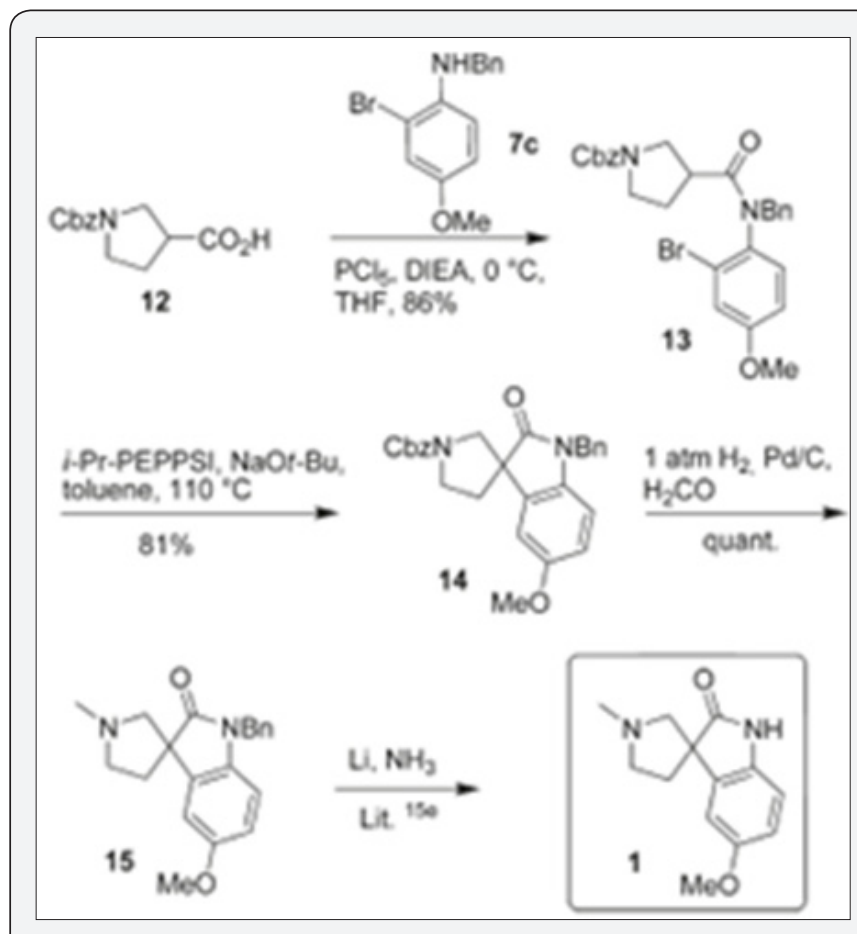

Figure 18 : Total synthesis of Horsfiline.

\section{Conclusion}

Wen-Ting Wei, have developed a base- and metal-free $\mathrm{C}$ $\left(\mathrm{sp}^{3}\right)$-H hydroxylation of 2-oxindoles. The reaction is promoted by TEMPO (2, 2, 6, 6-tetramethylpiperidine $\mathrm{N}$-oxide) and synthesized under atmospheric air as a hydroxylation reagent in THF (tetrahydrofuran) at room temperature. Reaction mechanism proposed involves TEMPO reacting with the enol form of the 2-oxindole, followed by a reaction with 02 that generates a superoxide anion have developed and efficient enantio and diastereoselective strategy of synthesizing diverse 64 compounds with inclusion of 15 oxindoles scaffolds and 49 triazole containing oxindoles and isatins. They have remarkable discoveries of pharmaceutical leads or biological potent. They have also demonstrated that catalytic asymmetric synthesis of oxindoles and spirooxinndoles was retained as a result of 
functionalization with CuAAC reaction and enabling to provide proficient methods to prepare vast enantiometrically enriched spirocyclic compounds. Daisuke S in 2008 studied the highly enantio selective catalytic hydroxylation of 3 -substituted oxindoles was obtained employing a phase-transfer catalyst with molecular oxygen as an oxidant. The product on conversion yielded an optically active compound, which was a synthetic precursor of alkaloid CPC-1. Takashi Ooi 2017 studied the Conversion of hydrogen peroxide into an electrophilic hydroxylating agent by activation with an electrophile can be an indigenous pattern to achieve hydroxylation of nucleophilic reagents, such as enolates, specifically if the transformation can be performed in a stereo controlled manner. Deppermann have uutilized the intramolecular Pdcatalyzed $\alpha$-arylation of anilides to the synthesize of 3,3 '- pyrrolidinyl-spirooxindoles. The authors found the [Pd]-PEPPSI-catalyst system would be the best for conversion of functionalized heterocyclic derivatives. Their methodology was found worth for the synthesis of spirooxindole natural products as has been investigated with the synthesis of ( \pm )-horsfiline.

\section{References}

1. Clardy J, Walsh C (2004) Lessons from natural molecules. Nature 432(7019): 829-837.

2. Paterson I, Anderson EA (2005) The renaissance of natural products as drug candidates. Science 310(5747): 451-453.

3. Schreiber SL (2005) Small molecules: the missing link in the central dogma. Nat Chem Biol 1: 64-66.

4. Gough JD, Crews CM (2007) Using natural products to unravel cell biology. Chem Biol 1: 95-114.

5. Hung DT, Jamison TF, Schreiber SL (1996) Understanding and controlling the cell cycle with natural products. Chem Biol 3(8): 623639.

6. Spring DR (2005) Chemical genetics to chemical genomics: small molecules offer big insights. Chem Soc Rev 34(6): 472-478.

7. Peddibhotla S, Dang Y, Liu JO, Romo D (2007) Simultaneous arming and structure activity studies of natural products employing o h insertion: an expedient strategy for natural products based chemical genetics. $J$ Am Chem Soc 129: 12222-12231.

8. Marti C, Carreira EM (2003) Construction of spiro[pyrrolidine-3 3 '-oxindoles] recent applications to the synthesis of oxindole alkaloids. Eur J Org Chem 12: 2209-2219.

9. Galliford CV, Scheidt KA (2007) Pyrrolidinyl spirooxindole natural products as inspirations for the development of potential therapeutic agents. Angew Chem Int Ed 46: 8748-8758.

10. Gary EA, Abel SG, Annaliese KF (2012) Catalytic Stereoselective Synthesis of Diverse Oxindoles and Spirooxindoles from Isatins. ACS Comb Sci 14(4): 285-293.

11. Denmark SE, Fu J (2003) Catalytic enantioselective addition of allylic organometallic reagents to aldehydes and ketones. Chem Rev 103(8): 2763-2794.

12. Marshall JA (2000) Synthesis and reactions of allylic allenic vinyli, and arylmetal reagents from halides and esters via transient organopalladium intermediates. Chem Rev 100(8): 3163-3186.

13. Nair V, Ros S, Jayan CN, Pillai BS (2004) Indium and gallium mediated carbon carbon bond forming reactions in organic synthesis. Chem Inform 35(22).
14. Lindström UM (2002) Stereoselective organic reactions in water. Chem Rev 102(8): 2751-2772.

15. Alcaide B, Almendros P, RodriguezAcebes R (2005) Metalmediated entry to functionalized 3-substituted 3-hydroxyindolin-2-ones via regiocontrolled carbonylallylation bromoallylation 1,3 butadien 2ylation propargylation or allenylation reactions of isatins in aqueous media. J Org Chem 70(8): 3198-3204.

16. Cravotto G, Giovenzana GB, Palmisano G, Penoni A, Pilati T, et al. (2006) Convolutamydine A: the first authenticated absolute configuration and enantioselective synthesis. Tetrahedron Asymm 17: 3070-3074.

17. Zhu WM, Bao WH, Ying WW, Chen WT, Huang YL (2018) TEMPOPromoted $\mathrm{C}\left(\mathrm{sp}^{3}\right)-\mathrm{H}$ Hydroxylation of 2-Oxindoles at room temperature. Asian J Org Chem 7(2): 337-340.

18. Daisuke S, Kazuhiro N, Takashi I (2008) Catalytic Asymmetric Hydroxylation of Oxindoles by Molecular Oxygen Using a Phase Transfer Catalyst. Org Lett 10(8): 1593-1595.

19. Peddibhotla S (2009) 3-Substituted-3-hydroxy-2-oxindole, an Emerging New Scaffold for Drug Discovery with Potential Anti-Cancer and other Biological Activities. Current Bioactive Compounds 5(1): 2038.

20. Daisuke T, Kenzo Y, Motomu K, Masakatsu S (2008) Enantioselective Synthesis of SM-130686 Based on the Development of Asymmetric $\mathrm{Cu}(\mathrm{I}) \mathrm{F}$ Catalysis To Access 2-Oxindoles Containing a Tetrasubstituted Carbon. J Am Chem Soc 131(20): 6946-6948.

21. Ke S, Xiaohua L, Lili L Xiaoming F (2012) Recent progress in enantioselective synthesis of C3-functionlized oxindoles: rare earth metals take action. J Chem Sci 3(2): 327-334.

22. Zuo J, Liao YH, Zhang XM, Yuan WC (2012) Organocatalyzed enenatioselective decarboxylative stereoablation reaction for the construction of 3,3 '-disusbstituted oxindoles using $\beta$-ketoacids and 3-halooxindoles. J Org Chem 77(24): 11325-11332.

23. Takashi, Ooi, Keiji, Maruoka (2007) Recent advances in Asymmetric Phase Transfer Catalysis. Angew Chem Int 46(23): 4222-4266.

24. Davis FA, Chen BC (1992) Asymmetric hydroxylation of enolates with n sulfonyloxaziridines. Chem Rev 92(5): 919-934.

25. Jian Z, Zhi Jun W, Jian Qiang Z, Ming Qiang Z, Xiao Ying X, et al. (2015) Preparation of 3-Sulfonylated 3,3-Disubstituted Oxindoles by the Addition of Sulfinate Salts to 3-Halooxindoles, J Org Chem 80(1): 634640.

26. K Ohmatsu, Y Ando, T Ooi (2017) In Situ Electrophilic Activation of Hydrogen Peroxide for Catalytic Asymmetric $\alpha$-Hydroxylation of 3-Substituted Oxindoles: Synlett 28(11):1291-1294.

27. Jacob PM, Joseph JB, Gary EA, Abel SG, Annaliese KF (2012) catalytic stereoselctive synthesis of diverse oxindoles and spirooxindoles from isatins. ACS Comb Sci 14(4): 285-293.

28. Hillgren JM, Marsden (2008) SP Convenient Synthesis of 3-Alkoxy-3aryloxindoles by Intramolecular Arylation of Mandelic Amides. J Org Chem 73(16): 6459-6461.

29. Ishimaru T, Shibata N, Nagai J, Nakamura S, Toru T (2006) Lewis acid-catalyzed enantioselective hydroxylation reactions of oxindoles and $\alpha$-keto esters using dbfox ligand. J Am Chem Soc 128(51): 1648816489.

30. Lee S, Hartwig JF (2001) Improved catalysts for the palladium-catalyzed synthesis of oxindoles by amide a-arylation. Rate acceleration, use of aryl chloride substrates, and a new carbene ligand for asymmetric transformations. J Org Chem 66(10): 3402-3415.

31. Chang MY, Pai CL, Kunga YH (2005) Synthesis of ( $( \pm)$-coerulescine and a formal synthesis of $( \pm)$-horsfiline. Tetrahedron Letters 46(49): 84638465. 
32. Deppermann N, Thomanek H, Prenzel AHGP, Maison W (2010) PdCatalyzed Assembly of Spirooxindole Natural Products: A Short Synthesis of Horsfiline. J Org Chem 75(17): 5994-6000.

33. Sano D, Nagata K, Itoh T (2008) Catalytic asymmetric hydroxylation of oxindoles by molecular oxygen using a phase transfers catalyst. Org Lett 10(8): 1593-1595.

34. Miah S, Moody CJ, Richards IC, Slawin AMZ (1997) Synthesis of the marine dibromooxoindoline Convolutamydine C. J Chem Soc Perkin Trans 1: 2405-2412.
35. Shaughnessy KH, Hamann BC, Hartwig JF (1998) Palladium-catalyzed inter- and intramolecular alpha-arylation of amides. Application of intramolecular amide arylation to the synthesis of oxindoles. $\mathrm{J} \mathrm{Org}$ Chem 63(19): 6546-6553.

36. Jossang A, Jossan P, Hadi HA, Sevenet T, Bodo B (1991) Total Synthesis of Horsfiline. J Org Chem 56: 6527.

\section{Your next submission with Juniper Publishers} will reach you the below assets

- Quality Editorial service

- Swift Peer Review

- Reprints availability

- E-prints Service

- Manuscript Podcast for convenient understanding

- Global attainment for your research

- Manuscript accessibility in different formats

( Pdf, E-pub, Full Text, Audio)

- Unceasing customer service

Track the below URL for one-step submission https://juniperpublishers.com/online-submission.php 